DOI: $\underline{10.7242 / 2658-705 X / 2019.2 .7}$

УДК 81.33

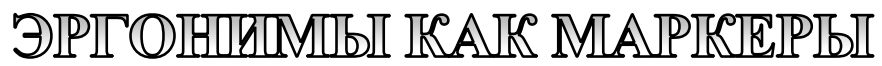

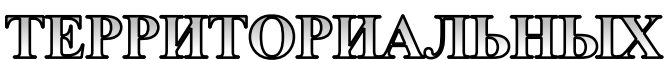

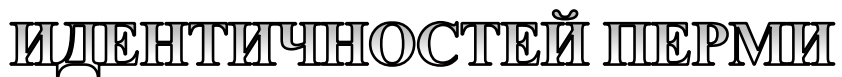

М.В. Назукина, Пермский федеральный исследовательский центр УрО РАН; Пермский государственный наџиональный исследовательский университет

\begin{abstract}
Исследование нацелено на систематизацию соотносимых с территориальной идентичностью названий организаций Перми как идентификаторов множественной идентичности. Анализ сосредоточен на изучении тех объектов, которые наделены наименованиями и/или иными особенностями, отражающими состояние локальной, региональной или макрорегиональной территориальной идентичности. Единицами анализа стали названия региона и города, имена культурных героев, символы региона. Проведенный контент-анализ названий организаций через справочник 2 ГИС позволил выделить доминирующие группы, содержащие маркер «Пермь», «Урал», «Прикамье» и др. Показано, что административное имя «Пермь» является самым распространенным территориальным идентификатором эргонимов. По итогам исследования зафиксирована слабая персонификация названий организаций с именами региональных героев (Строгановы как доминирующее название). Сделан вывод об укорененности эргонимов, связанных с маркером «Урал». Рассмотрено распространение территориальных идентификаторов в названиях пермских жилых комплексов (ЖК), и установлено слабое их использование при доминировании локальных и районных названий ЖК.
\end{abstract}

Ключевые слова: территориальная идентичность; локальная идентичность, нейминг, эргонимы, Пермь.

\section{Введение}

Изучение характеристик и соотношения территориальных идентичностей в настоящее время является одной из важных проблем научного знания при анализе региональных и локальных социальнополитических процессов. Чувство места и низовой патриотизм влияют на развитие территории, стимулируют социально-экономическое развитие. Цель настоящей статьи - выявление и уточнение характерных особенностей распространения территориальных идентичностей в границах Перми на примере изучения эргони- мов. Актуальность исследования заключается в рассмотрении вопроса о необходимости общего теоретического исследования эргонимов, анализа их характеристик, закономерностей возникновения как инструментов политики идентичности. Особенность изучения наименований связана с их исключительным разнообразием и количеством. Исследование нацелено на систематизацию соотносимых с территориальной идентичностью названий предприятий и объектов социальной и коммерческой инфраструктуры в Перми как идентификаторов множественной 
территориальной идентичности. Под социальными и коммерческими объектами инфраструктуры понимаются муниципальные, государственные или частные (коммерческие или некоммерческие) учреждения или заведения, которые созданы для оказания публичных услуг. Анализ сосредоточен на изучении тех объектов, которые наделены наименованиями и/или иными особенностями, отражающими состояние локальной, региональной или макрорегиональной территориальной идентичности. Фокус на городском уровне (случай Перми) в исследовании связан с анализом локальной идентичности, которая на сегодняшний день является доминирующим уровнем территориальной идентификации в России, и Пермском крае, в частности [14].

\section{Теоретические основы}

\section{и методы исследования}

Большинство научных исследований, посвященных эргонимам в региональном и городском пространстве, выполнены в рамках филологического подхода и на материалах крупных российских регионов и городов: Краснодарского края [15], Уфы [6], Москвы и Воронежа [11], Екатеринбурга [4, 5], Махачкалы [2] и др. Принципы образования эргонимов в г. Перми ранее затрагивались в работах М.В. Бобровой [3] и Т.А. Сироткиной [13]. В частности, в работах Т.А. Сироткиной выделены доминирующие эргонимы Пермского края, имеющие в основе топонимов Пермь и Кама, а также эргонимы, привязанные к Уралу [13, 53].

Большое значение для понимания роли эргонимов в локальной идентичности городов имеют работы зарубежных исследователей по топонимике. В них показано, как наименования отражают особенности самосознания и фиксируют отношение к месту жителей территории [1].

Само понятие эргонима было впервые определено в словаре Н.В. Подольской как «собственное имя делового объединения людей, в том числе союза, организации, учреждения, корпорации, предприятия, общества, заведения, кружка» [12]. Как отмечает Т.В. Федотова, эргоним является обобщенным понятием, так как каждый из объектов (научных, учебных, производственных учреждений и т.п.) выполняет свои функции и «номинация любого из названных объектов должна быть мотивирована в зависимости от цели функционирования конкретного объекта» $[15,86]$.

По мнению Р.И. Козлова, специфика локализованных предприятий заключается в том, что они являются не только эрго-, но и топообъектами, то есть частями городского пространства. Поэтому он предложил использование термина «эргоурбоним» с целью подчеркнуть «двойственный характер объекта номинации, который представляет, с одной стороны, деловое предприятие (для названия которого используется эргоним), а с другой объект городского пространства (номинируемый урбонимом/урбанонимом)» $[4,7]$.

Указанное уточнение фиксирует важную связь эргонимов с локальными идентичностями. В частности, принимая решение о наделении названием какой-либо организации или фирмы, человек рационально, в большей или меньшей степени, может использовать территориальные идентификаторы (название территории, символы, имена героев и пр.).

В самом общем виде локальную идентичность можно концептуализировать и как объективированные выражения местной уникальности, такие, например, как историко-культурный контекст, на основе которого «вырастает» самосознание жителей, и как механизмы использования этих особенностей через политику по их конструированию. Это, с одной стороны, характеристики уникальности места, которые можно описать формулой: «о чем жители думают как о чем-то общем» (ментальность и картина мира, сложив- 
шиеся в рамках города нарративы, мифологемы, обычаи, диалекты, общие повседневные практики); с другой стороны сознательное изобретение и использование городской уникальности в целях реализации политических интересов.

В структуре территориальной идентичности эргонимы занимают место семиотических средств номинации компонентов феномена. Они связаны с культурой и историей народа и, следовательно, с одной стороны, характеризуют доминирующие в общественном сознании символические маркеры идентичности места, а с другой, когда речь идет о наименовании или переименовании (нейминге), - могут являться инструментом символизации пространства.

\section{Результаты исследования}

Объектом нашего исследования являлись названия кампаний (фирм, филиалов и пр.) и объектов инфраструктуры (коммерческих и социальных предприятий, например магазинов, ресторанов, кафе и пр.). По данным информационного справочника 2 ГИС $^{1}$, методом контентанализа выявлялись названия организаций, имеющие территориальный маркер. В качестве возможных вариантов наименований рассматривались названия, получившие распространение в общественном мнении пермяков [9].

\section{Имена региона в названиях}

Принципиальным аспектом для оценки соотношения территориальных идентичностей в силу двойственного географического маркирования региона (традиционная принадлежность региона к Уралу при административном отнесении к Приволжскому федеральному округу; а также исторически укорененное соперничество Перми и Екатеринбурга как центров влияния и притяжения) являлось фиксирование распространения названий, имеющих маркер «Урала» («Западного Урала»), «Прикамье» и «Поволжье».

Методика работы со справочником 2 ГИС заключалась в определении частоты распространения выделенных названий через строку поиска и оценку их соотношения друг с другом, а также аналогичным исследованием 2015 года [10].

Как видно из табл. 1., самым распространенным территориальным маркером названий организаций является имя города «Пермь» и региона «Пермский» («Пермэнерго», «Пермкоммуналсервис» и др.). На втором месте стоит макрорегиональный идентификатор традиционной принадлежности региона к Уралу (например, гостиница «Урал», компания «Уралалко» и др.).

\section{Таблица 1}

Доминирующие названия региона
в нейминге пермских организаций
\begin{tabular}{|l|c|}
\hline Название & Количество \\
\hline Пермь/Пермский & 2714 \\
\hline Урал/Уральский & 774 \\
\hline Западный Урал & 34 \\
\hline Прикамье/Прикамский & 123 \\
\hline Парма & 64 \\
\hline Поволжье/Приволжский & 13 \\
\hline
\end{tabular}

Стоит особо отметить пару названий «Западный Урал - Прикамье» (например, Западно-Уральский машиностроительный концерн, Прикамские отделения банков ВТБ 24, Росбанка), которые рассматриваются как неформальные вторые имена Пермского края. Зафиксированная нами в 2015 году тенденция вытеснения традиционного уральского названия Пермского края как Западного Урала внутренним именем «Прикамье», подтверждается и в 2019 году. Степень распространения маркера «Прикамье» на январь 2015 года в два раза превышала использование названия «Западный Урал» (102 против 48). Спустя четыре года, в 2019 году, снижение названия «Западный Урал» стало еще более ощутимо (124 против 34). На наш взгляд, это связано с общим вектором

\footnotetext{
${ }^{1}$ Пермь. 2 ГИС. На март 2019 года в справочнике числится 57100 компаний/филиалов.
} 
отказа от уральского позиционирования в связи с отнесением региона к Приволжскому федеральному округу.

Отдельно стоит отметить эргоним «Парма», который становится более распространенным в Пермском регионе. Вопервых, Парма связана с Пермью Великой или Биармией, древней территорией, со своей мифологией, отчасти отраженной в историческом романе Алексея Иванова «Сердце Пармы» о покорении Перми Великой. А. Иванов, фактически создал и осмыслил для Пермского региона основания для пермской идентичности, которые заложены в историческом прошлом. Во-вторых, мифологический потенциал имени связан также с Коми-округом, который традиционно часто именуется Пармой. Втретьих, увеличение символического капитала данного имени для Пермского региона связано с появлением новой баскетбольной команды «Парма». Указанные факторы в комплексе создают загадочный образ Пармы и объясняют популярность названия.

\section{Символы Перми в названиях}

Кама является значимым символическим атрибутом пермской идентичности. Проявляется это не только в неформальном названии региона Прикамье, но и в распространении названия реки в нейминге организаций. Справочник 2 ГИС выдает 114 единиц с названиями, в которых содержится маркер «Кама» (Камкабель, Кама бассейн, Кама банный комплекс, клиника КамаМед, ресторан-клуб Кама Space Jam и др.).

Другой важный идентификатор - медведь (14 названий) уступает Каме, но при этом часто используется в названиях спортивных команд (физкультурно-спортивный клуб «Пермские медведи»).

\section{Персоналистские аспекты эргономики}

Наряду с названием и символами региона важным маркером идентичности являются персоналистские идентификато- ры или культурные герои территории личности, известные земляки, связанные своими корнями с регионом и впоследствии получившие всероссийское или мировое признание. Увековечивание наследия это человека в региональном пространстве осуществляется не только через монументализацию (установку памятников), но и через переименование и наименование. Имея дело с присвоением какому-либо объекту имени культурного героя, региональное сообщество рефлексирует по поводу достижений этого человека и соотносит себя с ценностными характеристиками, которые транслируют это имя.

В целом, в названиях самыми распространенными (табл. 2) являются исторические герои Строгановы («Строгановская сауна»; «Строгановская вотчина» ресторан, бар; база отдыха «Строгановские просторы») и Ермак (ДЮСШ «Ермак», строительный магазин «Ермак», финансовая группа «Ермак»).

Tаблиц̧а
Наиболее значимые культурные герои
Пермского края в названиях организаций
\begin{tabular}{|l|c|}
\hline Название & Количество \\
\hline Строганов & 7 \\
\hline Ермак & 7 \\
\hline Дягилев & 4 \\
\hline Славянов & 2 \\
\hline Солдатов & 1 \\
\hline Татищев & 1 \\
\hline Попов & 1 \\
\hline
\end{tabular}

Из деятелей культуры значимо имя театрального и художественного деятеля Сергея Дягилева (гимназия № 11 им. С.П. Дягилева, дом-музей семьи Дягилевых, арт-отель Дягилев, кафе Дягилев). В качестве примеров единичной персонификации можно привести названия, увековечивающие имена: А.С. Попова (Пермский радиотехнический колледж им. А.С. Попова), Н.Г. Славянова (мемориальный дом-музей Н.Г. Славянова, Пермский политехнический колледж им. Н.Г. Славянова, ПМЗ им. Н.Г. Славянова), А.Г. Солдатова (Пермский городской дворец культуры им. А.Г. Солдатова). 
Названия пермских ЖК как отражение территориальной идентичности

Часто названия жилых комплексов (ЖК) складываются исторически в зависимости конкретного места и адреса его расположения. Мода на названия ЖК сравнительно недавняя тенденция, по которой тоже можно фиксировать выраженность территориальной идентичности. Выбирая название, таким образом, застройщики позиционируют объект, подчеркивая «географические преимущества локации» [8]. Кроме того, территориальная идентичность может фигурировать при выборе названия ЖК в честь известной личности, связанной с территорией. Еще один вариант - использование значимых символических атрибутов места.

Из 84 жилых комплексов Перми, зафиксированных справочником 2 ГИС, территориальный маркер присутствует в 24 названиях. Самая большая группа названий связана с локальными идентичностями - названиями районов, микрорайонов, улиц города (ЖК «Мотовилихинsky (Мотовилихинский)», ЖК «Спортивный микрорайон Ива», ЖК «Грибоедовский», ЖК «Балатовский», ЖК «Черняховский квартал», ЖК «Водники», ЖК «Боровики», ЖК «Дружба», ЖК «Красавинский» и др.) Название региона зафиксировано лишь в одном ЖК - ЖК «Цветы Прикамья».

Вторая группа - персонифицированных названий: ЖК «Татищев» (в честь основателя Перми В.Н. Татищева), ЖК «Любимов» (в честь известного пермского предпринимателя, мецената и общественного деятеля И.И. Любимова), ЖК «Чехов» (в честь известного писателя А.П. Чехова, дважды бывавшего в Перми), Компаунд Живаго (по роману Бориса Пастернака «Доктор Живаго»).

Символические названия ЖК отражают символы региона («Пермские медведи») и отсылают к производственной (ЖК «Авиатор», ЖК «Astra (Астра)») и исторической идентичности города (ЖК «Губерния», ЖК «Солдатская слободка», ЖК «Арсенал» (район Красные казармы)).

Отдельно стоит отметить ЖК «Новый центр», который относится к первой группе названий, связанных с локальными идентичностями, но вместе с тем маркирующим новые амбиции, в плане позиционирования центра города (символическое название). Микрорайон Новый центр жилой комплекс на ул. Революции, который появился в 2018 году, напротив - гипермаркет «Семья». Наименование «Новый центр» стало использоваться пермяками и по отношению к ближайшей территории ${ }^{2}$. Напротив жилого комплекса был установлен арт-объект - большая световая надпись: «Новый центр». Таким образом, выбор названия может способствовать решению задач брендирования локальных объектов городского пространства.

\section{Заключение}

Рассматривая закономерности пермских эргонимов, имеющих отношение к территориальной идентичности, можно констатировать, что идентификация объекта выстраивается по отношению к пространству, к истории Перми и Пермского края. Административно-исторический эргоним (Пермь) превалирует в названиях организаций, в которых отражен маркер территории. Значительным является тяготение к Уралу и смыслам уральской макрорегиональной идентичности, вступающей в символическую конкуренцию с поволжской идентичностью. Например, показательно решение, принятое в начале 2018 года руководством ПАО Сбербанка России о ликвидации

\footnotetext{
${ }^{2}$ По мнению застройщика, «впервые в Перми брендирование жилого объекта дало такой сильный эффект». См: В центре Перми появился новый арт-объект // Талан, 22.ноября 2018 [Электронный pecypc] - URL: https://xn--e1 aohf5d.xn--80aa6ajv.xn--p1ai/journal/v-centre-permi-novyj-art-obekt (дата обращения: 25.03.2019).
} 
Западно-Уральского филиала, и отнесении Пермского края в структуру ВолгоВятского банка, что показывают динамку отхода от уральского маркера.

Кроме того, в нейминге Перми слабо использованы персонифицированные маркеры пермской идентичности, выраженные в именах культурных героев. Использование известных личностей носит в большинстве случаев единичный характер, тем не менее, фиксируя значение имени Строгановых в пермской истории, как наиболее часто встречающееся имя.

Аналогично слабо маркеры территориальности используются пермскими строительными компаниями при приня- тии решения о наименовании строящихся жилых комплексов, предпочитая использование имен известных личностей вне территориального пермского контекста (ЖК «Моцарт», ЖК «Онегин», ЖК «Маяковский») и просто яркие названия (ЖК «Рубин», ЖК «Верба», ЖК «Аврора», ЖК «Дом А» и др.). Как представляется, это ниша потенциально наиболее приближенная к повседневной жизни человека в городском пространстве, выражаемая в формуле «это мой дом», тесно связана с локальными низовыми идентичностями города и может через нейминг способствовать росту низового патриотизма.

\section{Библиографический список}

1. Helleland B. Place Names as Identity Markers Oslo Studies in Language. - 2012. - № 4(2). Names and Identities. [Электронный pecypc] - URL: https://yorkspace.library.yorku.ca/xmlui/ bitstream/handle/10315/3986/icos23_501.pdf?sequence=1\&isAllowed=y (дата обращения: 02.04.2019).

2. Алистанова Ф.Ф. Эргонимы современного русского языка как микросистема: автореф. дис... канд. филол. наук - Махачкала, 2011. [Электронный ресурс] - URL: http://www.dslib.net/russkijjazyk/jergonimysovremennogo-russkogo-jazyka-kak-mikrosistema.html (дата обращения: 02.04.2019).

3. Боброва M.В. Принципы образования современных эргонимов г. Перми. [Электронный ресурc] - URL: http://docplayer.ru/37697366-Bobrova-m-v-permskiy-gosudarstvennyy-gumanitarno-pedagogicheskiyuniversitet-perm-principy-obrazovaniya-sovremennyh-ergonimov-g.html (дата обращения: 06.04.2019).

4. Голомидова М.В. Образ пространства и пространственные образы в названиях старого Екатеринбурга // Изв. Урал. ун-та. Гуманит. науки. - Вып. 4. - 2001. - № 2. - С. 19-25.

5. Гузикова В.B. Отражение региональных особенностей в эргонимах города Екатеринбурга // Проблемы общей и региональной ономастики: материалы IX Междунар. науч. конф. - Майкоп: АГУ, 2014. - С. 90-94.

6. Емельянова А.M. Эргонимы в лингвистическом ландшафте полиэтнического города: автореф. дис... канд. филол. наук. - Уфа, 2007. [Электронный ресурс] - URL: http://cheloveknauka.com/ergonimy-vlingvisticheskom-landshafte-polietnicheskogo-goroda (дата обращения: 06.04.2019).

7. Козлов Р.И. Эргоурбонимы как новый разряд городской ономастики: автореф. дис... канд. филол. наук. - Екатеринбург, 2000.

8. Леденко В. Как назвать жилой комплекс, чтобы он привлекал покупателей? // KOLORO, 19.02.2018 [Электронный ресурс] - URL: https://koloro.ru/blog/brending-i-marketing/kak-nazvat-zhiloy-komplekschtoby-on-privlekal-pokupateley.html (дата обращения: 06.04.2019).

9. Назукина М.B. Особенности региональной идентичности Пермского края: социокультурный аспект // Вестник Пермского научного центра. - 2010. - № 1. - С.64-77.

10. Назукина М.В. Уральский макрорегион в системе территориальных идентичностей современной России // Известия РАН. Сер. Географическая. - 2015. - № 6. C.37-47. DOI:10.15356/0373-2444-2015-6-37-47.

11. Овсянникова K.В. Региональные аспекты нейминга предприятий общественного питания (сравнительная характеристика эргонимов г. Москвы и г. Воронежа) // Филол. науки. Вопросы теории и практики. - Тамбов: Грамота. - 2014. - № 7 (37): в 2 ч. Ч. II. - С. 156-159.

12. Подольская Н.В. Словарь русской ономастической терминологии. - М., 1988. - 192 с.

13. Сироткина T.A. Эргонимы в лингвокультурном пространстве Пермского края // Лингвокультурное пространство Пермского края: материалы и исследования / гл. ред. И.И. Русинова; под общ. ред. М.В. Бобровой; Перм. гос. нац. исслед. ун-т. - Пермь, 2015. - Вып. 4. - С. 52-60.

14. Территориальная идентичность на постсоветском пространстве // ЦИРКОН. Пресс-релиз, 15.03.2013. [Электронный $\quad$ pecypc] - $\quad$ URL: http://www.zircon.ru/upload/iblock/222/ PR_territorialnaja_identichnost_na_PSP_15-03-13.pdf(дата обращения: 06.04.2019). 
15. Федотова Т.В. Репрезентация региональной идентичности в эргонимическом поле Кубани // Политическая лингвистика. - 2016. - № 6 (60). - С. 85-90. [Электронный ресурс] - URL: http://elar.uspu.ru/bitstream/uspu/5114/1/plin-2016-06-09.pdf (дата обращения: 06.04.2019).

\title{
ERGONYMS AS MARKERS OF PERM TERRITORIAL IDENTITIES
}

\author{
M.V. Nazukina \\ Perm Federal Research Centre UB RAS \\ Perm State National Research University
}

The study aims at systematizing the names of Perm organizations correlated with territorial identity as identifiers of multiple identity. The analysis focuses on studying the objects that are endowed with names and/or other features that reflect the state of local, regional or macro-regional territorial identity. The units of analysis include the names of the region and the city, the names of cultural heroes, the symbols of the region. The content analysis of the names of organizations through the online directory 2 GIS allowed to identify the dominant groups of names containing the markers «Perm», «Ural», «the Kama River region», etc. The study shows that the administrative name «Perm» is the most common territorial identifier of ergonyms. According to the results of the study, a weak personification of the names of organizations with the names of regional heroes (the Stroganovs as the dominant name) was recorded. The conclusion is made about the inculcation of ergonyms related to the marker «Ural». The study also observes the dissemination of territorial identifiers in the names of Perm housing complexes identifying their rare use with the dominance of local and regional names.

Keywords: territorial identity, local identity, naming, ergonyms, Perm.

\section{Сведения об авторе}

Назукина Мария Викторовна, кандидат политических наук, научный сотрудник отдела по исследованию политических институтов и процессов, Пермский федеральный исследовательский центр УрО РАН (ПФИЦ УрО РАН), 614990, г. Пермь, ул. Ленина, 13А; доцент кафедры политических наук, Пермский государственный национальный исследовательский университет (ПГНИУ), 614990, г. Пермь, ул. Букирева, 15; e-mail: nazukina@mail.ru 